\title{
Crenças de aprendizagem de línguas e a formação reflexiva do professor
}

\author{
Bernadette Barbara Sebastian Barga Bomfim (BOMFIM, Bernadette B. S. B.) \\ Mestre em Lingüística Aplicada pela Universidade de Brasília - UnB \\ barbara.bomfim@gmail.com \\ Mariney Pereira Conceição (CONCEIÇÃO, Mariney P.) \\ Professora Doutora da Universidade de Brasília - UnB \\ mariney_pereira@yahoo.com.br
}

\begin{abstract}
Resumo
Neste artigo, discutimos a importância do construto crenças, seu conceito e características, destacando a importância das crenças na formação reflexiva de professores de línguas. Ressaltamos, através de uma discussão das relações entre crenças, experiências, contexto e a prática do professor, a importância da reflexão acerca das crenças e suas implicações para o processo de formação de professores. Duas implicações podem ser levantadas a partir das discussões aqui propostas: a primeira refere-se à influência que as crenças e experiências anteriores de aprendizagem podem exercer sobre a prática pedagógica do professor, baseado em Johnson (1994), Richards e Lockhart (1996) e Zeichner (1983, 1999); e a segunda trata do papel do contexto de ensino como uma força que interage com as crenças do professor e, conseqüentemente, com sua prática docente.
\end{abstract}

Palavras-chave: ensino e aprendizagem de línguas, crenças de aprendizagem de línguas, formação de professores.

\begin{abstract}
In this article, we discuss the importance, concepts, and characteristics of beliefs, highlighting their significance for reflection in language teacher education, by presenting a theoretical review of studies on the relationship between beliefs, experience, context, and teacher practice. The assumptions presented call attention to the importance of the construct and implications for language teacher education: first, that experiences and beliefs affect teachers' actions, according to Johnson (1994), Richards and Lockhart (1996), and Zeichner (1983, 1999); and second, the contexts in which teachers operate interact with their beliefs and consequently with their teaching practices.
\end{abstract}

Keywords: language learning and teaching, beliefs about language learning, teacher education. 


\section{Introdução}

As crenças têm se tornado um conceito importante para várias áreas do conhecimento que buscam compreender as ações humanas. Na área da Filosofia da Ciência, Kuhn (2006, p. 220) esclarece, no posfácio de seu livro A Estrutura das Revoluções Científicas, que utiliza o termo 'paradigma' em dois sentidos e que um desses refere-se à constelação de 'crenças', valores e técnicas partilhadas pelos membros de uma determinada comunidade. O autor afirma que a ciência inclui um conjunto de crenças e que nenhuma comunidade científica pode trabalhar sem cogitá-las (KUHN, 2006, p. 21-23).

$\mathrm{Na}$ área da Psicologia Social, Fishbein e Ajzen (1975) propuseram a Teoria da Ação Intencional, um modelo conceitual que tenta compreender a relação entre crenças, atitudes, intenção e comportamento. Nesse modelo, as crenças são centrais em cada disciplina relacionada ao comportamento humano e aprendizagem. Elas funcionam como base informacional que influencia os comportamentos de uma pessoa. Segundo os autores (p. 12,131), as crenças vinculam atributos a um objeto que, dentre outros, pode ser uma pessoa ou grupo de pessoas, uma idéia ou um comportamento.

$\mathrm{Na}$ área da educação, Nespor (1987) sugere um modelo para o estudo de crenças. $\mathrm{O}$ autor aponta que crenças podem agir individualmente ou em sistemas. A compreensão das origens, bem com a estrutura das crenças de professores seria imprescindível na compreensão da sua prática de ensino, uma vez que as crenças se inter-relacionam com estruturas cognitivas e estratégias metacognitivas para definir tarefas relacionadas com o ensino e para solucionar problemas enfrentados no processo de ensino e aprendizagem.

No âmbito do ensino e aprendizagem de línguas estrangeiras (LE), Bernat e Gvozdenko (2005) apontam que o termo crenças em relação à aprendizagem de línguas foi usado pela primeira vez por Papalia (1978). Trata-se de um artigo intitulado Students' beliefs on the importance of foreign languages in the school curriculum que relata os resultados da aplicação de um questionário aos alunos da $9^{\circ}$ série do Condado de Erie em Nova York, com o objetivo de identificar o que pensavam sobre a importância do ensino de LE na grade curricular da escola. Os resultados apontaram que os alunos acreditavam que as LE ocupavam um lugar importante no currículo escolar e que ajudavam a compreender melhor as culturas estrangeiras e a sua própria língua.

As crenças são também componentes fundamentais no trabalho de formar professores de línguas (ALMEIDA FILHO, 2006), pois se relacionam, de maneira complexa, com a prática (BARCELOS, 2004; JOHNSON, 1994; ZEICHNER, 1999) e com o contexto de ensino (BORG, 2003).

O objetivo deste artigo é discutir a importância da reflexão sobre as crenças no processo de formação do professor de línguas. Para isso, apresentamos, inicialmente, a definição e alguns pressupostos básicos em relação ao construto crenças, discorrendo, na seqüência, acerca do processo de formação e origem das crenças. Discutimos, ainda, as relações entre crenças e experiências, e crenças e prática de ensino, ressaltando, também, a importância do contexto na relação entre crenças e ações do professor. Destacamos, por fim, a importância da reflexão sobre crenças no processo de formação de professores de línguas. 


\section{Definições e alguns pressupostos sobre crenças}

Horwitz (1988) usou o termo crenças para se referir a idéias ou noções preconcebidas sobre aspectos de Aquisição de Segunda Língua (ASL). Wenden (1986b) refere-se ao termo crenças como um "termo técnico [...] para [...] opiniões, que são baseadas em experiências e opiniões de outras (pessoas) respeitadas, e que influenciam a maneira como agem" (p. 5). ${ }^{1}$ Ainda, baseando-se na literatura da área da Psicologia Cognitiva, Wenden (1986a, p. 186) equipara o termo crenças com conhecimento metacognitivo, que seria definido como conhecimento estável, declarável e falível de um aprendiz sobre o próprio processo cognitivo. Por sua vez, Wenden (1999, p. 436) afirma que crenças seria um termo que poderia ser usado alternadamente com conhecimento metacognitivo. Como um subconjunto do conhecimento metacognitivo, as crenças do aprendiz podem ser apropriadamente descritas em termos das características que identificam o conhecimento metacognitivo. No entanto, a autora afirma que as crenças "são distintas do conhecimento metacognitivo, uma vez que implicam uma valorização e tendem a receber forte adesão"² (WENDEN, 1999, p. 436).

Em outros estudos (KALAJA, 1995; SAKUI; GAIES, 1999), observa-se uma tentativa em definir o termo por meio de uma especificação quanto à sua formação, função e características. Por exemplo, Sakui e Gaies (1999) afirmam que crenças são produtos de experiências de aprendizagem formal e informal e que as mesmas funcionam como determinantes de futuras aprendizagens. Kalaja (1995) define as crenças como processos interativos, socialmente construídos e inseridos em um contexto maior, que podem variar de acordo com o aprendiz e com o contexto. A autora também afirma que crenças podem ou não influenciar a aprendizagem de línguas.

A pluralidade na conceituação do termo crenças foi o foco de um estudo extensivo de Pajares (1992) que concluiu que a confusão em relação à definição do termo crenças era geralmente centrada na distinção entre crenças e conhecimento. Clandinin e Connelly (1987) examinaram as origens, usos e significados de construtos pessoais de conhecimento utilizados em pesquisas acerca de crenças de professores. Como resultado, os autores identificaram uma gama de termos, incluindo 'critério de ensino do professor', 'princípios de prática', 'perspectiva / construto / teoria / epistemologia / crenças pessoais', 'concepções dos professores', 'conhecimento pessoal', 'conhecimento prático'. Assim, concluíram que a distinção entre crenças e conhecimento era difícil de determinar e que a maioria dos construtos era, na verdade, simplesmente diferentes palavras querendo dizer a mesma coisa.

Pajares (1992) parece sugerir, ao concluir seu estudo, que a proliferação de várias definições em relação às crenças ajudou a esclarecer e detalhar o conceito, tanto que, a partir dessa pluralidade, estabelecem-se alguns pressupostos que poderiam fundamentar outros estudos em relação às crenças. Apresentamos, a seguir, alguns desses pressupostos enumerados por Pajares (1992, p. 324-326).

- As crenças são formadas cedo e tendem a se perpetuarem, persistindo mesmo perante contradições causadas por razão, tempo, instrução, ou experiência;

\footnotetext{
${ }^{1}$ Texto original: Give them the 'technical term' for what they have been discussing: these opinions which are based on experience and the opinions of respected others, which influence the way they act, can be called beliefs. (WENDEN, 1986b, p. 5)

${ }^{2}$ Texto original: [...] they are value-related and tend to be held more tenaciously. (WENDEN, 1999, p. 436)
} 
- As crenças são priorizadas em relação às outras crenças ou estruturas cognitivas e afetivas;

- As crenças podem influenciar o comportamento;

- As crenças devem ser inferidas. A inferência das crenças deve considerar a congruência entre o discurso, a intenção de agir, e a ação em si.

Barcelos (2004), por sua vez, define crenças como

[...] forma de pensamento, como construções da realidade, maneiras de ver e perceber o mundo e seus fenômenos, co-construídas em nossas experiências e resultantes de um processo interativo de interpretação e (re)significação. Como tal, crenças são sociais (mas também individuais), dinâmicas, contextuais e paradoxais. (BARCELOS, 2004, p. 18)

Em um ensaio teórico que apresenta as principais tendências atuais de investigação de crenças sobre ensino e aprendizagem, Barcelos (2006) resume sete características da natureza das crenças como são concebidas atualmente. São elas: dinâmicas (mudam de um período para outro); emergentes; socialmente construídas e situadas contextualmente (não são estruturas mentais prontas e fixas, mudam, desenvolvem-se com a interação e com as mudanças de experiências); experienciais (resultado de interação entre indivíduo e ambiente); mediadas (instrumentos que podem ser usados ou não dependendo da situação); paradoxais e contraditórias (podem agir como instrumentos de empoderamento ou como obstáculos para o ensinoaprendizagem); não tão facilmente distintas do conhecimento; e relacionadas à ação de maneira indireta ou complexa (não necessariamente influenciam ações).

Nota-se que algumas constatações atuais sobre a natureza de crenças (BARCELOS, 2004) corroboram os pressupostos afirmados nos estudos revisados por Pajares (1992). Nota-se, também, que a ênfase atual do caráter social e contextual das crenças é consistente com o terceiro momento no desenvolvimento dos estudos sobre crenças, descrito por Barcelos (2004), no qual há uma maior preocupação com o contexto.

\section{Crenças sobre aprendizagem de LE}

Em Barcelos (2004, p. 130), observa-se que o conceito de crenças de aprendizagem de LE abrange idéias como concepções dos alunos sobre a língua, a aprendizagem, e o processo de aprendizagem de línguas (WENDEN, 1986b), concepções dos alunos sobre como a linguagem opera e conseqüentemente é aprendida (ABRAHAM; VANN, 1987), concepções dos alunos sobre seus papéis e funções dos professores e dos materiais do ensino (HOLEC, 1987), concepções dos alunos sobre toda a tarefa de aquisição de uma segunda língua (GARDNER, 1988), concepções dos alunos sobre a natureza, estrutura e uso da língua, relação entre linguagem e pensamento, linguagem e inteligência, linguagem e aprendizagem (RILEY, 1994).

Vários pesquisadores (BARCELOS, 2006, 2007; BERNAT; GVOZDENKO, 2005; BORG, 2003) destacam o número crescente de estudos a respeito de crenças. Inicialmente focalizadas na identificação de crenças e na análise da sua influência na aprendizagem dos alunos e na prática de ensino do professor de LE, pesquisas avançam atualmente na direção de temas mais específicos no processo de ensino e aprendizagem 
de LE, como crenças sobre leitura, vocabulário, gramática, entre outros (BARCELOS, 2006, 2007).

Resultados de pesquisas sobre crenças na área de LA ressaltam implicações, não apenas para o processo de ensino-aprendizagem de LE em si, mas também para a formação dos professores da área (BARCELOS, 2000; BARCELOS; BATISTA; ANDRADE, 2004; BORG, 2003; HORWITZ, 1988; WENDEN, 1999), especialmente no que diz respeito à formação reflexiva dos futuros professores de LE. Como exemplo, Barcelos et al. (2004) sugerem a importância de os professores de Letras conhecerem os tipos de crenças que seus alunos trazem no curso de formação inicial para que possam preparar atividades e estruturar seu curso de maneira que promovam a discussão e o questionamento em relação às crenças, procurando propor soluções e modelos que possam servir de tópicos de discussão e reflexão no curso.

Se é verdade que os professores pensam, fazem escolhas e tomam decisões baseadas em um sistema de conhecimento, pensamentos e crenças e que esse sistema é complexo, pessoal e baseado na prática e no contexto (CALDERHEAD, 1996), precisamos compreender as origens das crenças e como essas se formam, desde os momentos iniciais no processo de educação e formação do professor de línguas.

\section{Formação e origem das crenças}

Borg (2003) atribui a formação da cognição do professor a quatro fatores: (1) experiência anterior de aprendizagem; (2) experiência profissional; (3) fatores contextuais; e (4) a própria prática de ensino do professor.

Para Richards e Lockhart (1996, p. 30-32), os sistemas de crenças são baseados nos objetivos, valores e crenças do professor em relação ao conteúdo e ao processo de ensino, a sua compreensão do sistema no qual trabalha e o seu papel dentro dele. Essas redes de crenças e valores servem como antecedentes de suas decisões e ações e constituem sua cultura de ensinar. Conforme os autores, as crenças podem ser simples ou complexas, são formadas gradualmente e derivam de várias fontes: (1) experiência como aprendiz; (2) experiência sobre o que funciona melhor no ensino; (3) prática de ensino pré-estabelecida; (4) personalidade; (5) princípios originados de pesquisa; e (6) princípios provenientes de uma abordagem ou método de ensino.

A experiência é um fator fundamental na formação das crenças. Uma maior compreensão das crenças do professor implica, portanto, uma compreensão das mesmas a partir das experiências, como discutiremos a seguir.

\section{Crenças e experiência}

Para Dewey (1933, apud CONCEIÇÃO, 2004), dois fatores são fundamentais na constituição das experiências: 1) a interação do indivíduo com outros indivíduos e com seu meio; e 2) a conexão entre experiências passadas e futuras.

Vários estudos (FISHBEIN; AJZEN, 1975) realizados nos anos setenta parecem dar sustentação aos pressupostos que estabelecem a importância da experiência na formação da cognição de uma pessoa. Fishbein e Ajzen (1975) defendem a tese de que as crenças são formadas por meio da experiência e observação direta. Essa tese é corroborada pela teoria Sócio-Cognitiva de Bandura (1977), segundo a qual o desenvolvimento cognitivo de seres humanos ocorre por meio da experiência direta, ou seja, o indivíduo aprende por fazer (enactive learning) e por observação (vicarious learning). As perspectivas construtivistas de Piaget e de Vygotsky (cf. WOOLFOLK, 
2001) também reconhecem a influência da experiência na construção do conhecimento e crenças.

Em termos de ensino/aprendizagem, Lortie (1975) afirma que professores aprendem sobre ensino pela experiência de aprendizagem, o que o autor denomina de ' 13.000 horas de aprendizagem pela observação' (13,000-hour apprenticeship of observation', ou seja, as horas e horas que os professores de LE vivem como alunos, podem exercer uma grande influência na formação das suas crenças a respeito do processo de ensino-aprendizagem. Muitas dessas crenças, que existiam desde a formação inicial, podem persistir e influenciar a prática de ensino do professor ao longo de sua carreira (FREEMAN, 1996a, 1996b). Essas crenças, apesar da formação inicial e da formação continuada, podem resistir a mudanças (JOHNSON, 1994), perpetuandose, assim, os mesmos modelos de ensino através dos quais os professores aprenderam (BAILEY et al., 1996).

Johnson (1994) investigou, por meio de narrativas, as crenças de professores préserviço de L2 e o ensino de L2. O resultado indica que as crenças dos informantes emergem das imagens conflitantes sobre professores e prática de ensino que adquiriram durante a experiência de aprendizagem. Conseqüentemente, no estudo, as tomadas de decisões dos professores pré-serviço durante a prática de ensino foram baseadas nessas crenças.

Vieira-Abrahão (2004) sugere que, na formação pré-serviço, o aluno-professor traz uma experiência rica como aprendiz e, às vezes, já como professor, além de todas as outras experiências de vida. Segundo a autora, poucos alunos tiveram a oportunidade de refletir sobre suas próprias crenças acerca do ensino/aprendizagem da língua que pretendem ensinar. Com base nessa observação, a autora desenvolveu um estudo envolvendo seis alunos de Letras a fim de criar uma oportunidade para que eles pudessem explicitar suas crenças. Para a autora, as origens das crenças dos participantes podem ser traçadas nas suas experiências prévias de aprendizagem e ensino. Por exemplo, as imagens que os participantes do estudo tinham sobre o que é um professor eram, provavelmente, construídas a partir dos melhores e piores professores que tiveram.

Hyland e Anan (2006) investigaram o tratamento de erros realizado por diferentes professores. O estudo utilizou, como instrumento de coleta de dados, uma tarefa de correção do texto escrito por um aluno de LE, bem como um questionário. Os autores analisaram as crenças e prática de correção de três grupos de participantes - professores nativos de inglês, professores de inglês não nativos, e falantes nativos de inglês que eram leigos, mas altamente escolarizados. Os dados coletados indicam que, embora todos os professores considerassem a correção de erro como uma estratégia pedagógica positiva, estes executaram a tarefa de maneiras diferentes, por terem crenças distintas sobre a correção de erro e concepções variadas sobre o que seja erro de produção de texto. Hyland e Anan (2006) atribuem as crenças sobre correção de erro dos professores às suas experiências anteriores com a língua e níveis de desempenho na mesma.

Ainda Oliveira (2007) investigou como a formação teórico-prática de três professoras de LE contribuiu para a sua preparação para a experiência em sala de aula em escola pública. Neste estudo, o depoimento de uma das professoras deixou claro que, no início de sua carreira, a sua prática era baseada no que observou nos professores com quais estudou.

Bailey et al. (1996) relatam um projeto colaborativo entre sete mestrandas e um professor formador, que, por meio de diários autobiográficos e reflexões sobre os mesmos, investigaram a influência da experiência de aprendizagem na formação dos seus princípios e prática de ensino. Os autores, que, antes do estudo haviam afirmado 
que não davam muita importância às características e comportamento dos seus professores no passado, por meio da redação das autobiografias, destacaram que suas experiências prévias de aprendizagem haviam influenciado seus critérios de julgamento sobre o que seria uma aprendizagem sucedida ou fracassada, e, também, suas idéias a respeito do ensino e do professor bom ou ruim, entre outras. Os autores concluíram, assim, que a experiência funciona, de fato, como guia na prática de ensino do professor.

Da mesma maneira, Conceição (2004) relaciona, não apenas experiência e crenças, mas experiência e ação. Num estudo que procurou analisar as relações entre experiências, crenças e ações na aprendizagem de LE, especificamente em relação ao uso de dicionário pelos alunos, a autora sugere que as experiências anteriores influenciam a formação de crenças, bem como a ação em si. Incluímos, portanto, na seqüência, uma discussão acerca das relações entre crenças e a prática de ensino do professor de línguas.

\section{Crenças e prática de ensino}

Como vários estudiosos (BARCELOS, 2006; BORG, 2003; FISHBEIN; AJZEN, 1975; PAJARES, 1992; VIEIRA-ABRAHÃO, 2004) sugerem, a importância dos estudos acerca de crenças reside no pressuposto de que crenças influenciam a ação.

Pesquisas relacionadas às crenças do professor procuram estabelecer relações entre essas crenças e sua prática de ensino. A definição de prática de ensino utilizada aqui é a de Almeida Filho (1993), o qual destaca que esta consiste de quatro dimensões que são intimamente ligadas: planejamento das unidades da aula, produção de materiais de ensino, regência e avaliação.

Estudos que procuram relacionar crenças e ação pressupõem que as crenças dos professores influenciam sua prática e as interações na sala de aula (JOHNSON, 1994; ZEICHNER, 1999). Por outro lado, alguns estudos indicam, também, que a prática dos professores não necessariamente refletem suas crenças. Woods (2003, p. 207) ressalta que "[...] o que dizemos que acreditamos nem sempre é o fator que influencia nossas ações, e pessoas podem realizar ações que parecem ser inconsistentes com o que dizem ser suas crenças". ${ }^{3}$ Ou seja, pode haver dissonância entre as crenças do professor e a sua prática. Borg (2003, p. 94) destaca que

as práticas dos professores também são moldadas pelas realidades psicológicas, sociais e ambientais da escola e da sala de aula [...] esses fatores incluem os pais, exigências dos diretores, a escola, a sociedade, o currículo, sala de aula e instalação da escola e políticas da escola, colegas, exames padronizados, e a disponibilidade dos recursos. Evidências sugerem que tais fatores também podem impedir a habilidade dos professores de línguas em adotar práticas que refletem suas crenças. ${ }^{4}$

\footnotetext{
${ }^{3}$ Texto original: [...] what we say we believe may not always be the factor which influences our actions, and individuals can carry out actions which seem to be inconsistent with what they say their beliefs are. (WOODS, 2003, p. 207)

${ }^{4}$ Texto original: [...] teachers' practices are also shaped by the social, psychological and environmental realities of the school and classroom [...] these factors include parents, principals' requirements, the school, society, curriculum mandates, classroom and school layout, school policies, colleagues, standardized tests and the availability of resources. There is evidence to suggest that, unsurprisingly, such factors may also hinder language teachers' ability to adopt practices which reflect their beliefs. (BORG, 2003, p. 94)
} 
O autor acrescenta que essa dissonância não é necessariamente ruim, mas sim o resultado natural da interação constante entre escolhas pedagógicas de professores e suas percepções do seu contexto. Tillema e Kremer-Hayon (2005) sugerem que a dissonância entre crenças e contexto pode resultar em 'dilema'. Para as autoras, um dilema "denota um potencial para ação e escolha de estratégia de prática para administrar inconsistências entre crenças e prática" (p. 204). ${ }^{5}$

Barcelos (2006), baseando-se em Richardson (1996), aponta pelo menos três maneiras de entender a relação entre crenças e ação: (1) relação causa - efeito; (2) relação interativa; e (3) relação hermenêutica. Na primeira relação, as crenças influenciam as ações. Os professores adotam abordagens de ensinar que crêem ser mais efetivas. Se valorizar o ensino por tarefas, por exemplo, adotará técnicas que propiciem as mesmas. A relação interativa, por sua vez, prevê que não só as crenças podem influenciar as ações, mas as experiências e reflexões sobre as ações também podem influenciar a mudança nas crenças e/ou formação de novas crenças. Uma relação complexa entre contexto, crenças e ação é o que a relação hermenêutica sugere.

Como se pode observar, a relação entre crenças, contexto e ação é complexa. Nesse sentido, seria interessante, aqui, revermos alguns resultados de estudos que enfatizam essa complexidade. Farrell (2006), por exemplo, relata um estudo de caso que investigou um professor noviço de LE durante seu primeiro ano de serviço em Cingapura. Apesar de o estudo não focar especificamente crenças, é possivel notar, nos relatos, a interação entre crenças e prática. $\mathrm{O}$ autor relata que o professor/participante (Wee Jin) teve várias complicações, uma delas em relação a um conflito entre o que o professor almejava fazer em suas aulas e o que a instituição esperava dele. Wee Jin cria que a abordagem de ensino/aprendizagem centrada no aluno resultava na aprendizagem eficaz da língua e, portanto, queria adotar essa abordagem. No entanto, seus novos colegas na escola lhe informaram que a abordagem não iria funcionar na situação real da sala de aula. Por isso, Wee Jim acreditou que não seria fácil adotar tal ensino, uma vez que percebeu uma tradição de ensino centrada no professor entre os professores da escola. Para Wee Jin, era importante seguir as normas da escola que, nesse caso, proibiam o barulho e a perda de controle das turmas. Mas, mesmo assim, Wee Jin acreditava que podia conduzir aulas mais participativas. Pelo seu depoimento, parece que Wee Jin percebia que seus alunos gostavam da sua abordagem. Esse fato parece ter facilitado sua decisão de continuar com a mesma, apesar da cultura de ensinar da escola.

Lima (2006) investigou ainda a relação entre as crenças e expectativas trazidas por uma professora e seus alunos ao contexto escolar. A autora constatou, através dos dados coletados, que uma professora, apesar de indicar que não acreditava na realização de avaliação formal de aprendizagem, aplicava exatamente essa forma de prova como exigência do sistema de ensino em que lecionava. Desse modo, os dois estudos supracitados exemplificam dois tipos de relação entre crenças e ação. $\mathrm{Na}$ primeira, observa-se uma coerência entre crenças e ação, apesar do contexto. Já no segundo, observa-se uma dissonância entre crenças e ação, por motivo do contexto. Qual seria, então, o papel do contexto na relação entre crenças e ações?

\section{O papel do contexto na relação crenças - ação}

A análise da relação entre crenças e ação que propomos aqui baseia-se na idéia de que cognição e ação são situadas (WATSON-GEGEO, 2004). Tal perspectiva situa o

\footnotetext{
${ }^{5}$ Texto original: a dilemma denotes an action potential and opting for a practice strategy to manage inconsistencies between beliefs and practice. (TILLEMA; KREMER-HAYON, 2005, p. 204)
} 
pensamento e a ação dentro do contexto, e pressupõe que cada pensamento e ação humana são dependentes da situação em que ocorrem.

Gimenez (1994) faz uma ressalva a respeito de estudos que consideram a prática de ensino como nada mais que um processo cognitivo, sem nenhuma consideração quanto ao contexto. No que se refere à pesquisa em relação às crenças, a autora faz duas considerações: (1) que pesquisas sobre crenças do professor não estejam limitadas à descrição de crenças, e sim procurem compreender a relação das mesmas com a prática de ensino; e (2) que o papel do contexto seja considerado na análise dessa relação crenças-ação. Para a autora, algumas crenças podem permanecer no plano de abstração e não se transformam em ações observáveis, por causa das limitações contextuais. Assim sendo, possíveis inconsistências entre crenças e ações podem ser vistas como resultados de fatores contextuais e não de incoerências no pensamento do professor.

Da mesma maneira, também Borg (2003) reconhece que nem sempre as crenças do professor influenciam sua prática de ensino devido a fatores contextuais. Ajzen (2006) explicita a mesma visão, apontando que as crenças de uma pessoa geralmente resultam em uma intenção de agir de certa maneira. No entanto, quando a pessoa confere mais peso a fatores contextuais do que às próprias crenças, esta age em consonância com outra crença que seja mais coerente com a situação em que se encontra. Dessa forma, uma compreensão das relações entre crenças e ações com base nos fatores contextuais certamente permitirá que alcancemos uma visão mais completa e ao mesmo tempo menos estereotipada sobre a prática pedagógica do professor.

\section{As crenças e a formação do professor de línguas}

Nas últimas décadas, a formação de professores tem sido foco de vários esforços de reforma com base em determinados paradigmas teóricos, como, por exemplo, a formação artesanal, formação tecnicista e formação reflexiva (WALLACE, 1991; ZEICHNER, 1983). A concepção de formação reflexiva elege a reflexão como um requisito para o desenvolvimento profissional, supostamente substituindo a concepção de uma formação artesanal (observação e imitação) e formação tecnicista (aplicação da ciência).

No entanto, os conceitos de 'reflexão' e 'formação reflexiva' devem ser compreendidos como processos que incluem não apenas a 'reflexão-na-ação' (SCHÖN, 2000, p. 60-61), que é focalizada na ação em si, mas também na articulação das crenças e na reflexão sobre as mesmas em relação à prática e ao seu contexto (ZEICHNER, 1990). Nesse sentido, é interessante considerar, então, que a reflexão sobre crenças faz parte do modelo reflexivo de formação de professores (WALLACE, 1991).

Em termos gerais, no que se refere à formação de professores, o objetivo da reflexão é formar professores capazes de questionar seu contexto, analisar as origens e conseqüências das suas ações (ZEICHNER, 1983) e confrontar a teoria com a realidade da prática, contribuindo, portanto, com o avanço de conhecimento sobre o processo de ensino e aprendizagem, por meio da teorização das situações vividas (PAQUAY; WAGNER, 2001).

Calderhead e Gates (1993) destacam que programas que adotam um modelo reflexivo de formação de professores devem visar, entre outros aspectos, capacitar os professores a avaliarem as dimensões moral e ética implícitas na prática de sala de aula, incluindo a análise crítica das suas próprias crenças sobre seu conceito de bom ensino, assim como facilitar o desenvolvimento, pelos professores, das suas próprias teorias e princípios de prática de ensino, empoderando os professores a fim de poderem 
influenciar as direções futuras da educação e assumirem um papel mais ativo nas tomadas de decisões acerca da educação.

\section{Conclusões e considerações finais}

Neste artigo, discutimos a importância do construto crenças para o processo de formação de professores de línguas. Como proposto, a reflexão a respeito das crenças e da maneira como estas influenciariam a prática de ensino do professor, certamente, nos auxiliará na tarefa tão urgente que, como educadores, temos diante de nós: compreender, com maior clareza, os processos de ensinar e aprender línguas, buscando um ensino de línguas mais efetivo e de qualidade, quer seja nas esferas públicas de ensino no país ou nas esferas de ensino regular no contexto brasileiro.

Duas implicações em se tratando das crenças e sua relação com o processo de formação de professores podem ser levantadas a partir das discussões aqui propostas. A primeira refere-se à influência que as crenças e experiências anteriores de aprendizagem podem exercer sobre a prática pedagógica do professor (JOHNSON, 1994; RICHARDS; LOCKHART, 1996; ZEICHNER, 1983, 1999); a segunda trata do papel do contexto de ensino como uma força que interage com as crenças do professor e, conseqüentemente, com sua prática docente.

Assim, como já foi dito, a análise da relação entre crenças e ação que propomos aqui baseia-se na idéia de que cognição e ação são situadas (WATSON-GEGEO, 2004). Essa perspectiva situa o pensamento e a ação dentro do contexto, pressupondo que cada pensamento (e o desenvolvimento do pensamento) e cada ação humana, como por exemplo, a aprendizagem, são dependentes da situação em que ocorrem.

Em resumo, o que pretendemos ressaltar é que professores trazem para a sala de aula crenças, conhecimentos (teórico-prático) e experiências formados e adquiridos ao longo do tempo, e que estes contribuem para a construção da prática pedagógica dentro das possibilidades da realidade contextual em que se inserem em cada momento. Essa resultante dinâmica entre experiências, crenças, prática e contexto deve ser, portanto, considerada com mais atenção nos processos de formação de professores de línguas.

Diante dessas considerações, queremos argumentar que uma maior compreensão das crenças de futuros professores teria muito a contribuir para a formação de professores mais reflexivos e conscientes, não apenas de sua prática, mas também dos fatores que a informam, possibilitando, em termos mais abrangentes, uma melhor adequação de objetivos, conteúdos e procedimentos em sala de aula, conseqüentemente, redundando em maior eficácia no processo de ensino e aprendizagem de línguas no contexto de ensino brasileiro.

Paulo Freire (1979, p. 14) já argumentava que "[...] não é possível fazer uma reflexão sobre a educação sem refletir sobre o próprio homem”. Ousamos, então, acrescentar: nenhuma reflexão sobre a educação é possível sem que também possamos refletir sobre o que somos, o que pensamos e acreditamos, e sobre o professor que desejamos, de fato, nos tornar.

\section{Referências}

ABRAHAM, Roberta G.; VANN, Roberta J. Strategies of two language learners: a case study. In: WENDEN, Anita; RUBIN, Joan. (Eds.). Learner strategies in language learning. London: Prentice Hall, 1987. p. 85-102. 
AJZEN, I. TpB Diagram. 2006. Disponível em: $<$ www.people.umass.edu/aizen/tpb.html >. Acesso em: 28 nov. 2007.

ALMEIDA FILHO, José Carlos Paes de. Dimensões comunicativas no ensino de línguas. Campinas: Pontes, 1993.

. Prefácio. In: BARCELOS, Ana Maria F.; VIEIRA-ABRAHÃO, Maria Helena, Crenças e ensino de línguas. SP: Pontes, 2006. p. 7-8.

BAILEY, Kathleen, M.; BERGTHOLD, Bret; BRAUNSTEIN, Belinda; FLEISCHMAN, Natasha J.; HOLBROOK, Matthew P.; TUMAN, Jennifer; WAISSBLUTH, Ximena; ZAMBO, Leslie J. The language learner's autobiography: examining the "apprenticeship of observation". In: FREEMAN, Donald; RICHARDS, Jack. C. (Eds.). Teacher learning in language teaching. NY: Cambridge University Press, 1996. p. 11-29.

BANDURA, Albert. Social Learning Theory. Englewood Cliffs, NJ: Prentice Hall. 1977.

BARCELOS, Ana Maria F. Understanding teachers' and students' language learning beliefs in experience: a Deweyan approach. 2000. Tese (Doutorado em ensino de inglês como segunda língua) - College of Education, University of Alabama, Tuscaloosa, Alabama, USA, 2000.

. Crenças sobre aprendizagem de línguas, Lingüística Aplicada e ensino de línguas. Linguagem \& Ensino, v. 7, n. 1, p. 123-156, 2004.

Cognição de Professores e alunos: tendências recentes na pesquisa de crenças sobre ensino e aprendizagem de línguas. In: BARCELOS, Ana Maria F.; VIEIRAABRAHÃO, Maria Helena. Crenças e ensino de línguas. SP: Pontes, 2006. p. 15-41.

Crenças sobre ensino e aprendizagem de línguas: reflexões de uma década de pesquisa no Brasil. In: ALVAREZ, Maria Luisa Ortiz; SILVA, Kleber Aparecido. (Orgs.). Lingüística aplicada: múltiplos olhares. Brasília, DF: UnB; Campinas, SP: Pontes Editores, 2007. p. 20-27.

; BATISTA, Fernanda de Sá; ANDRADE, Juliane Cristina. Ser professor de inglês: crenças, expectativas e dificuldades dos alunos de Letras: In: VIEIRAABRAHÃO, Maria Helena (Org.). Prática de ensino de língua estrangeira: experiências e reflexões. Campinas, Pontes, 2004. p. 11-29.

BERNAT, Eva; GVOZDENKO, Inna. Beliefs about language learning: current knowledge, pedagogical implications, and new research directions. TESL-EJ, v. 9, n. 1, p. 1-21, 2005.

BORG, Simon. Teacher cognition in language teaching: a review of research on what language teachers think, know, believe, and do. Language Teacher, v. 36, p. 81-109, 2003. 
CALDERHEAD, James. Teachers: Beliefs and knowledge. In: BERLINER, David C.; CALFEE, Robert C. (Eds.). Handbook of educational psychology. New York: Macmillan. 1996. p. 709-725.

; GATES, Peter. (Eds.). Conceptualizing reflection in teacher development. London: Falmer Press, 1993.

CLANDININ, D. Jean; CONNELLY, F. Michael. Teachers' personal knowledge: what counts as "personal" in studies of the personal. Journal of Curriculum Studies, v. 17, p. 487-500, 1987.

CONCEIÇÃO, Mariney Pereira. Vocabulário e consulta ao dicionário: analisando as relações entre experiências, crenças e ações na aprendizagem de LE. 2004. Tese (Doutorado em Estudos Lingüísticos) - Faculdade de Letras, Universidade Federal de Minas Gerais, Belo Horizonte, 2004.

DEWEY, John. How we think. Boston: Heat, 1933.

FARRELL, Thomas. S. C. The first year of language teaching: imposing order. System, v. 34, p. 211-221, 2006.

FISHBEIN, Martin; AJZEN, Icek. Belief, attitude, intention, and behavior: an introduction to theory and research. Reading, MA: Addison-Wesley, 1975.

FREEMAN, Donald. The "unstudied problem": research on teacher learning in language teaching. In: __ RICHARDS, Jack C. (Eds.). Teacher learning in language teaching. Cambridge University Press, 1996a. p. 351-378.

Renaming experience/reconstructing practice: developing new understandings of teaching. In: __ RICHARDS, Jack C. (Eds.). Teacher learning in language teaching. Cambridge: Cambridge University Press, 1996b. p. 221-241.

FREIRE, Paulo. Educação e mudança. 16 ed. Rio de Janeiro: Paz e Terra, 1979.

GARDNER, Robert C. The socio-educational model of second learning: assumptions, finding, and issues. Language Learning, v. 38, n. 1, p. 101-126, 1988.

GIMENEZ, Telma. Learners becoming teacher: an exploratory study of beliefs held by prospective and practicing EFL teachers in Brazil. 1994. Tese (Doutorado) - Lancaster University, Lancaster, 1994.

HOLEC, Henri. The learning as manager: managing learning or managing to learn? In: WENDEN, Anita; RUBIN, Joan (Eds.). Learning strategies in language learning. London: Prentice Hall, 1987. p. 145-156.

The beliefs about language learning of beginning university foreign language students. The Modern Language Journal, n. 72, p. 283-294, 1988.

HYLAND, Ken; ANAN, Eri. Teachers' perceptions of error: the effects of first language and experience. System, v. 34, p. 509-519, 2006. 
JOHNSON, Karen E. The emerging beliefs and instructional practices of preservice English as a second language teachers. Teaching and Teacher Education, v. 10, n. 4, p. 439-52, 1994.

KALAJA, Paula. Student beliefs (or metacognitive knowledge) about SLA reconsidered. International Journal of Applied Linguistics, v. 5, n. 2, p. 191-204, 1995.

KUHN, Thomas S. A estrutura das revoluções científicas. Tradução de Beatriz Vianna Boeira e Nelson Boeira. 9. ed. São Paulo: Perspectiva, 2006.

LIMA, Solange, S. Crenças e expectativas de um professor e alunos de uma sala de quinta série e suas influências no processo de ensino e aprendizagem de inglês em escola pública. In: BARCELOS, Ana Maria F.; VIEIRA-ABRAHÃO, Maria Helena. Crenças e ensino de línguas. SP: Pontes, 2006. p. 147-162.

LORTIE, Dan C. Schoolteacher: a sociological study. Chicago: University of Chicago Press, 1975.

NESPOR, Jan. The role of beliefs in the practice of teaching. Journal of Curriculum Studies, v. 19, n. 4, p. 317-328, 1987.

OLIVEIRA, Elisa Pinto de. A relevância de se ensinar/aprender a língua inglesa na escola pública: o discurso de pais e alunos. 2007. Dissertação (Mestrado em Letras) Faculdade de Filosofia, Letras e Ciências Humanas, Universidade de São Paulo, São Paulo, 2007.

PAJARES, M. Frank. Teachers' beliefs and educational research: cleaning up a messy construct. Review of Educational Research, v. 62, n. 3, p. 307-332, 1992.

PAPALIA, Anthony. Students' beliefs on the importance of foreign languages in the school curriculum. Foreign Language Annals, v. 11, p. 21-23, 1978.

PAQUAY, Léopold; WAGNER, Marie-Cécile. Competências profissionais privilegiadas nos estágios e na videoformação. In: PERRENOUD, Philippe; PAQUAY, Léopold; ALTET, Marguerite; CHARLIER, Évelyne. (Orgs.). Formando professores profissionais: que estratégias? que competências? Tradução de Fátima Murad e Eunice Gruman. Porto Alegre: Artmed, 2001. p. 135-160.

RICHARDS, Jack. C.; LOCKHART, Charles. Reflective teaching in second language classrooms. Cambridge: Cambridge University Press, 1996.

RICHARDSON, Virginia. The role of attitudes and beliefs in learning to teach: In: SIKULA, John. (Org.). Handbook of research on teacher education. New York: Macmillan, 1996. p. 102-119.

RILEY, Philip. Aspects of learner discourse: why listening to learners is so important. In: ESCH, Edith. (Org.). Self-access and the adult language learner. London: Centre for information on language teaching. 1994. p. 7-18. 
SAKUI, Keiko; GAIES, Stephen J. Investigating Japanese learners' beliefs about language learning. System, v. 27, n. 4, p. 73-492, 1999.

SCHÖN, Donald A. Educando o profissional reflexivo. Um novo design para o ensino e a aprendizagem. Tradução de Roberto Cataldo Costa. Porto Alegre: Artes Médicas Sul, 2000 .

TILLEMA, Harm; KREMER-HAYON, Lya. Facing dilemmas: teacher-educators' ways of constructing a pedagogy of teacher education. Teaching in Higher Education, v. 10, n. 2, p. 203-217, 2005.

VIEIRA-ABRAHÃO, Maria Helena. Crenças, pressupostos e conhecimentos de alunosprofessores de língua estrangeira e sua formação inicial. In: VIEIRA-ABRAHÃO, Maria Helena. (Org.). Prática de ensino de língua estrangeira: experiências e reflexões. Campinas, Pontes, 2004. p. 131-152.

WALLACE, Michael J. Training foreign language teachers: a reflective approach. Cambridge: Cambridge University Press, 1991.

WATSON-GEGEO, Karen Ann. Mind, language, and epistemology: toward a language socialization paradigm for SLA. The Modern Language Journal, v. 88, p. 331-350, 2004.

WENDEN, Anita. What do second-language learners know about their language learning? A second look at retrospective accounts. Applied Linguistics, v. 7, n. 2, p. 86205, 1986a. $12,1986 \mathrm{~b}$.

Helping language learners think about learning. ELT Journal, v. 40, n. 1, p. 3. Metacognitive knowledge and language learning. Applied Linguistics, v. 19, n. 4, p. 515-537, 1999.

WOODS, Devon. The social construction of beliefs in the language classroom. In: KALAJA, P.; BARCELOS, Ana Maria F. (Orgs.). Beliefs about SLA: new research approaches. Dordrecht: Kluwer, 2003. p. 201-227.

WOOLFOLK, Anita. Educational psychology. 8th ed. MA: Allyn and Bacon, 2001.

ZEICHNER, Kenneth M. Alternative paradigms of teacher education. Journal of Teacher Education, v. 34, n. 3, p. 9-27. May/June 1983.

Changing directions in the practicum: looking ahead to the 1990s. Journal of Education for Teaching, v. 16, n. 2, p. 105-132, 1990.

. The new scholarship in teacher education. Educational Researcher, v. 28, n. 9, p. 4-15, 1999. 